\title{
The Introduction and Analysis of MTDC System
}

\author{
Xini Lou \\ North China Electric Power University \\ 3107059845@qq.com
}

Keywords: MTDC; Advantages; Topology; Wiring mode; Prospects

\begin{abstract}
With the development of the times, people's demand for electricity is increasing day by day, when the requirements become more stringent. Multi-Terminal Direct Current (MTDC) can achieve the function of Power transmission among multi power sources or multi receiving ends. And compared to conventional transmission systems, it is more economical and flexible as well as many other significant advantages. This paper focuses on the advantages of MTDC and its current situation. Then it analyzes the topological structure and wiring mode with tables and figures. And the development of this technology is prospected finally.
\end{abstract}

\section{Introduction}

The Main Advantages of MTDC. The Multi-Terminal HVDC Transmission System has received more and more attention, which not only have advantages of HVDC, but also make Multi-power supply and multi-drop power possible. The main advantages are summarized as follows.

1)Through a number of converter station access to power or load, it can transmit electricity to the island or multiple load center.

2)It could be used for the cross-regional communication system or multi-wind electric field interconnection of the DC power grid.

3)Increased reliability, flexibility and diversity of power supply.

Compared with two-terminal DC transmission, multi-terminal DC transmission system will be more economical and more flexible in the following occasions:

1)transporting large amounts of electricity from the energy base to multiple load centers in the distance;

2) DC transmission line intermediate branch access load or power supply;

3) to achieve non-synchronous network connection between several isolated communication systems by DC transmission lines.

Present Status of Development. The existing multi-terminal HVDC project are shown in Table 1. Italy - Corsica - Sardinia transmission project is the world's first multi-terminal HVDC project officially put into operation. Canada Quebec - New England 5-terminal DC system is currently the world's largest multi-terminal HVDC project. Japan's Shinshu 3-terminal DC transmission project is the world's first back-to-back voltage source converter multi-terminal HVDC project, achieved the interconnection between $50 \mathrm{~Hz}$ power grid in eastern part of Japan and the $60 \mathrm{~Hz}$ power grid in western. Canada Nelson River 4-terminal DC transmission by the two bipolar HVDC transmission system composed. [1,2,3,4,5]

Table 1 The situation of currently running MTDC projects

\begin{tabular}{llllll}
\hline $\begin{array}{l}\text { Serial } \\
\text { Nummer }\end{array}$ & MTDC Project & $\begin{array}{l}\text { Operating } \\
\text { Time }\end{array}$ & $\begin{array}{l}\text { Ports } \\
\text { Operating } \\
\text { Voltage }\end{array}$ & $\begin{array}{l}\text { Rated } \\
\text { Power }\end{array}$ \\
\hline 1 & Italy-Corsica-Sardinia & 1987 & 3 & $200[\mathrm{KV}]$ & $200[\mathrm{MW}]$ \\
2 & Canada Quebec - New England & 1992 & 5 & $\pm 500[\mathrm{KV}]$ & $2250[\mathrm{MW}]$ \\
3 & Japan's Shinshu & 2000 & 3 & $10.6[\mathrm{KV}]$ & $153[\mathrm{MW}]$ \\
4 & Canada Nelson River & 1985 & 4 & $\pm 500[\mathrm{KV}]$ & $3800[\mathrm{MW}]$ \\
5 & Pacific Liaison Line & 1989 & 4 & $\pm 500[\mathrm{KV}]$ & $3100[\mathrm{MW}]$ \\
\hline
\end{tabular}




\section{Analysis}

Topology. The development of multi-terminal HVDC needs to design DC power grid topology. There are four kinds of topology of DC power grid, which are radially, ring, simple mesh and complex mesh. The characteristics of the DC topology are shown in Table 2. The topology should be selected according to the number and location of the converter station, the energy distribution, the load characteristics and the robustness of the AC system.

Table 2 Characteristics of DC grid topology

\begin{tabular}{|l|l|l|}
\hline Topology & Advantages & Disadvantages \\
\hline Radiation topology & Simple, less investment, no DC bus & Poor reliability \\
\hline Ring topology & Structure and operation is simple & $\begin{array}{l}\text { poor reliability, } \\
\text { long distance, } \\
\text { large transmission loss }\end{array}$ \\
\hline simple mesh topology & Improved safety and reliability & $\begin{array}{l}\text { Slightly increased the } \\
\text { length of the line }\end{array}$ \\
\hline $\begin{array}{l}\text { complex mesh } \\
\text { topology }\end{array}$ & $\begin{array}{l}\text { High reliability, flexible power transmission, and } \\
\text { reduces the minimum connection distance between } \\
\text { DC nodes }\end{array}$ & Line long, high cost \\
\hline
\end{tabular}

Wiring mode. The wiring mode of Multi-Terminal HVDC Transmission System can be divided into parallel, series and mixed wiring (refer with: Fig. 1, Fig. 2, Fig. 3, Fig. 4). [1,2,3,4,5] At the same time the parallel type is divided into radio and ring wiring.

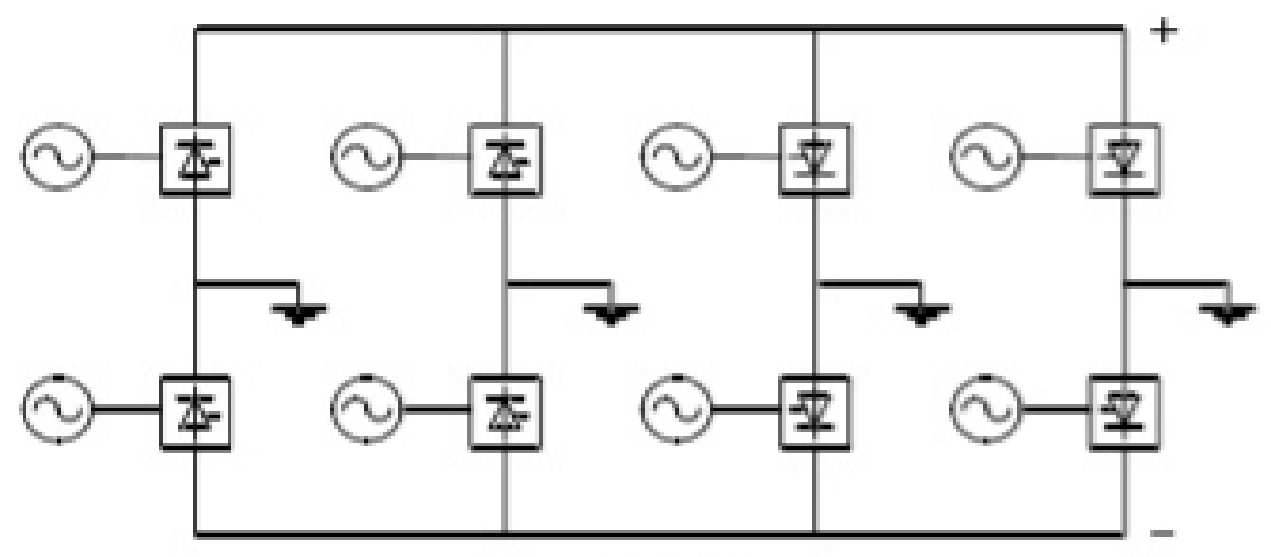

Figure 1. Radio parallel wiring

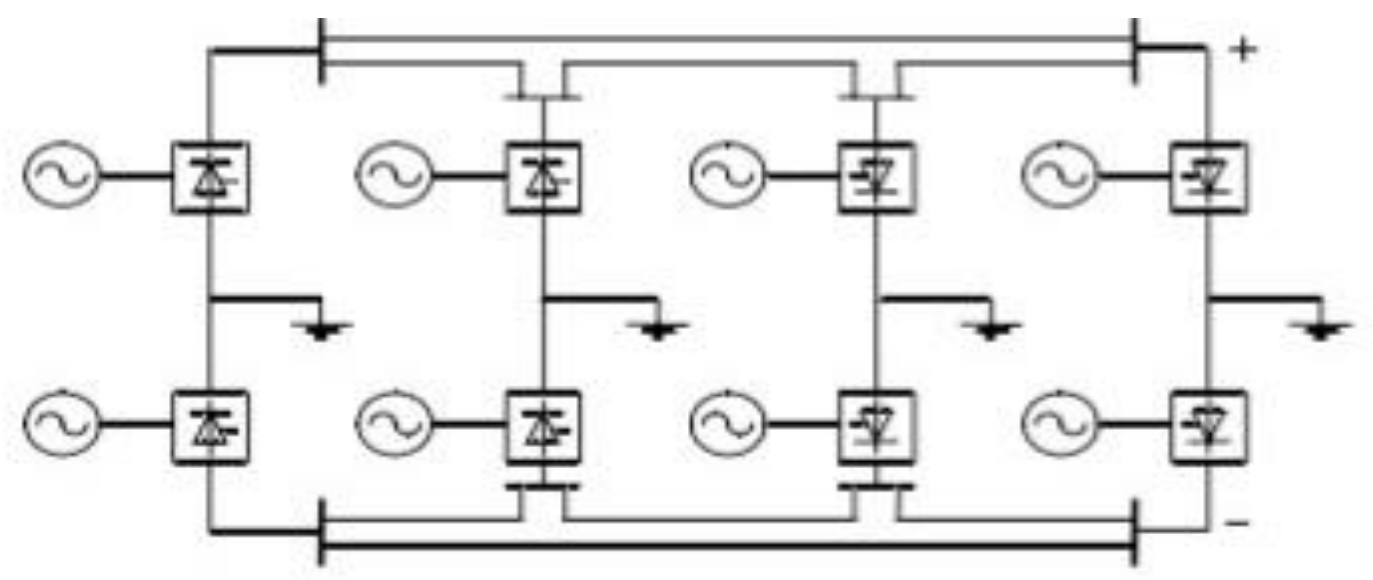

Figure 2. Ring parallel wiring 


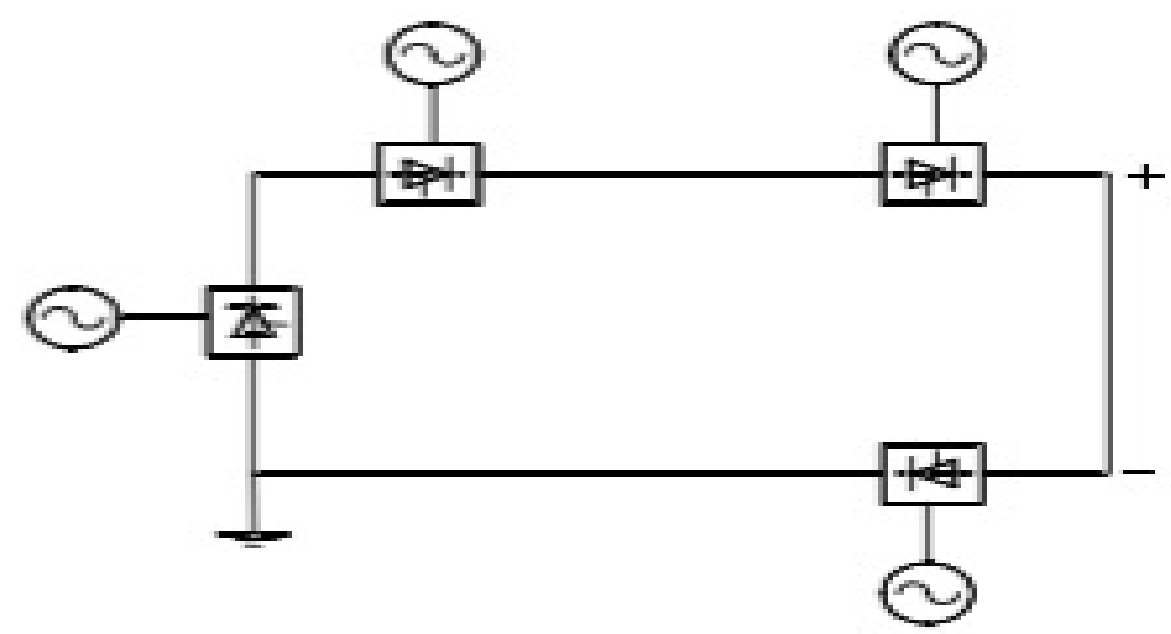

Figure 3. Series wiring

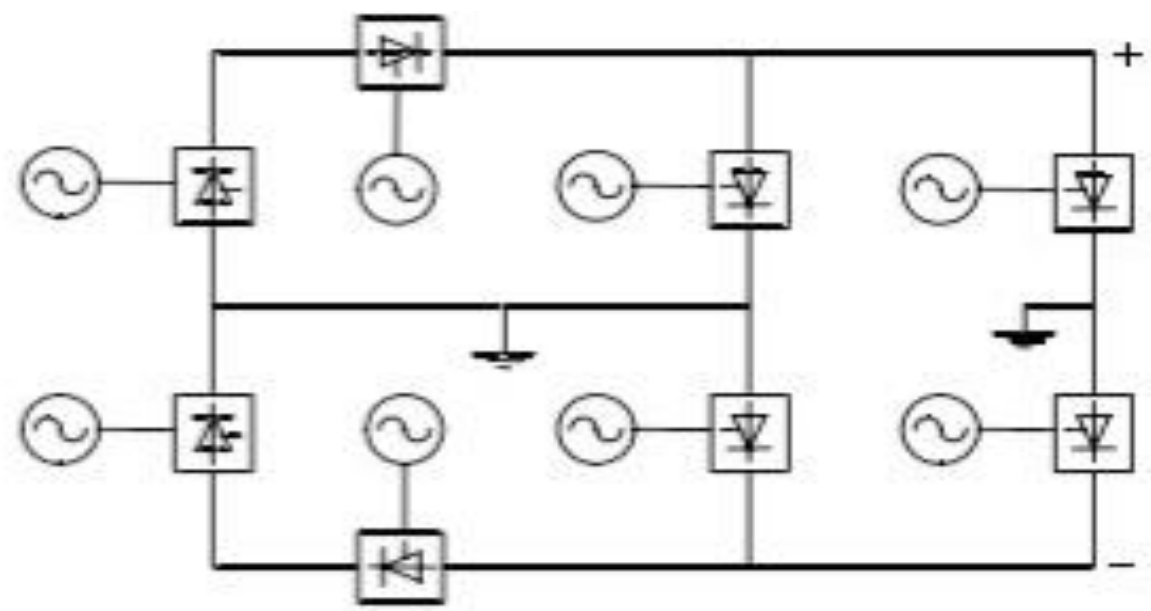

Figure 4. Mixed wiring

Parallel converter stations run with the same level of DC voltage, and power distribution is carried out by changing the current of each converter station; series converter stations run with the same level of DC current, and power distribution is carried out by changing the DC voltage. Both parallel and series mixed wiring mode increases the flexibility of the multi-terminal HVDC connection. In the design phase, it should be based on the analysis and comparison of investment, loss, reliability, flexibility, the specific requirements of projects and other aspects to choose the appropriate wiring.

In short, compared with the series mode, the parallel has smaller line loss, larger adjustment range, easier insulation, more flexible way of expansion and outstanding economy, so all the current operation of the multi-terminal HVDC transmission project are using parallel wiring.

\section{Prospects}

In some vast countries, such as the United States, China, India and Brazil Multi-Terminal HVDC Transmission will be the effective means to solve the problem of long-distance and high-capacity power transmission! For regional new energy grid integration and consumptive problem, MTDC also will be an effective supplement. Literature [6] studied the role of VSC-MTDC in urban DC distribution network. Literature [7] has proved that the mixed multi terminal HVDC system has good operation characteristics in the start-up, steady state operation, DC and AC fault situation. The 
control method for Multi-Terminal DC Transmission system based on MMC are analyzed in detail in Literature [8].

The next few decades will be the phase of rapid development of MTDC. As the capacity continues to increase, in some areas it will gradually replace the traditional transmission. $[6,9,10]$

\section{References}

[1] Teaching and research group of HVDC transmission of Zhejiang University: Direct Current Transmission (Water Conservancy and Electric Power Press, China 1985), p.155. (In Chinese)

[2] W.J. Zhao: HVDC Transmission Engineering Technology (China Electric Power Press, China 2004), p.459. (In Chinese)

[3] X.Y. Li: HVDC System (Science Press, China 2010), p.72. (In Chinese)

[4] Editorial Committee of China Electrical Engineering Committee: China Electrical Engineering Encyclopedia (China Electric Power Press, China 2010), p.186. (In Chinese)

[5] W.L. Zhang, Y. Tang and N.C. Zeng: North China Electric Power University, Vol.34 (2010) No.9, p.1000. (In Chinese)

[6] Information on http://ieeexplore.ieee.org/document/4596508/

[7] Q. Chen: Operation and Control of VSC Based Multi-terminal HVDC System (Ph.D., Southeast University, China 2007), p.1. (In Chinese)

[8] J. Hu: Research on Control Method for Multi-Terminal DC Transmission System Based on MMC (Ph.D., North China Electric Power University, China 2013), p.1. (In Chinese)

[9] Information on http://www.ieee.com

[10]L. Xu, BW Williams and L.Z. Yao: IEEE Power and Energy Society General Meeting (Pittsburgh,1-7,2008), Vol.1, p.1. (In Chinese) 